\begin{tabular}{|c|c|}
\hline Citation & $\begin{array}{l}\text { Philip Moons, Koen Luyckx, Jessie Dezutter, Adrienne H. Kovacs, Corina } \\
\text { Thomet, Werner Budts, Junko Enomoto, Maayke A. Sluman, Hsiao-Ling Yang, } \\
\text { Jamie L. Jackson, Paul Khairy, Raghavan Subramanyan, Luis Alday, Katrine } \\
\text { Eriksen, Mikael Dellborg, Malin Berghammer, Bengt Johansson, Andrew S. } \\
\text { Mackie, Samuel Menahem, Maryanne Caruana, Gruschen Veldtman, } \\
\text { Alexandra Soufi, Susan M. Fernandes, Kamila White, Edward Callus, Shelby } \\
\text { Kutty, Silke Apers, on behalf of the APPROACHIS consortium and the } \\
\text { International Society for Adult Congenital Heart Disease (ISACHD) }\end{array}$ \\
\hline & $\begin{array}{l}\text { Religion and spirituality as predictors of patient-reported outcomes in } \\
\text { adults with congenital heart disease around the globe } \\
\text { International Journal of Cardiology } 2019 ; 274: 93-99\end{array}$ \\
\hline Archived version & $\begin{array}{l}\text { Author manuscript: the content is identical to the content of the published } \\
\text { paper, but without the final typesetting by the publisher }\end{array}$ \\
\hline Published version & https://doi.org/10.1016/j.ijcard.2018.07.103 \\
\hline Journal homepage & https://www.journals.elsevier.com/International-Journal-of-Cardiology \\
\hline Author contact & $\begin{array}{l}\text { your email Philip.Moons@med.kuleuven.be } \\
\text { your phone number + } 32(0) 16373315\end{array}$ \\
\hline IR & \\
\hline
\end{tabular}

(article begins on next page) 


\section{Religion and Spirituality as Predictors of Patient-Reported Outcomes in Adults with Congenital Heart Disease Around the Globe}

Philip Moons, PhD, ${ }^{\mathrm{a}, \mathrm{b}, \mathrm{c}}$ Koen Luyckx, PhD, ${ }^{\mathrm{d}}$ Jessie Dezutter, PhD, ${ }^{\mathrm{d}}$ Adrienne H. Kovacs, $\mathrm{PhD},{ }^{\mathrm{e}, \mathrm{f}}$ Corina Thomet, MSc, ${ }^{\mathrm{g}}$ Werner Budts, MD, PhD, ${ }^{\mathrm{h}, \mathrm{i}}$ Junko Enomoto, PhD, ${ }^{\mathrm{j}}$ Maayke A. Sluman, MD, ${ }^{\mathrm{k}}$ Hsiao-Ling Yang, $\mathrm{PhD},{ }^{1}$ Jamie L. Jackson, $\mathrm{PhD},{ }^{\mathrm{m}}$ Paul Khairy, MD, PhD,${ }^{\mathrm{n}}$ Raghavan Subramanyan, MD, ${ }^{\mathrm{T}}$ Luis Alday, MD,${ }^{\mathrm{p}}$ Katrine Eriksen, MSc, ${ }^{\mathrm{q}}$ Mikael Dellborg, $\mathrm{MD}, \mathrm{PhD},{ }^{\mathrm{c}, \mathrm{r}, \mathrm{s}}$ Malin Berghammer, $\mathrm{PhD},{ }^{\mathrm{c}, \mathrm{t}}$ Bengt Johansson, MD, PhD, ${ }^{\mathrm{u}}$ Andrew S. Mackie, MD, ${ }^{\mathrm{v}}$ Samuel Menahem, MD, ${ }^{\mathrm{w}}$ Maryanne Caruana, MD, ${ }^{\mathrm{x}}$ Gruschen Veldtman, MD, ${ }^{\mathrm{y}}$ Alexandra Soufi, MD, ${ }^{\mathrm{z}}$ Susan M. Fernandes, LPD, PA-C, ${ }^{\text {aa }}$ Kamila White, PhD, ${ }^{\text {ab }}$ Edward Callus, $\mathrm{PhD},{ }^{\text {ac }}$ Shelby Kutty, MD, PhD, ${ }^{\text {ad }}$ Silke Apers, $\mathrm{PhD},{ }^{\mathrm{a}}$ on behalf of the APPROACHIS consortium and the International Society for Adult Congenital Heart Disease (ISACHD)

Total word count: 2814 words

Brief title: Religion and spirituality in congenital heart disease

${ }^{a}$ KU Leuven Department of Public Health and Primary Care, KU Leuven - University of Leuven, Leuven, Belgium

${ }^{\mathrm{b}}$ Institute of Health and Care Sciences, University of Gothenburg, Gothenburg, Sweden

${ }^{c}$ Department of Paediatrics and Child Health, University of Cape Town, Cape Town, South Africa

${ }^{\mathrm{d}}$ School Psychology and Child and Adolescent Development, KU Leuven - University of Leuven, Leuven, Belgium 
e Peter Munk Cardiac Centre, University Health Network, University of Toronto, Toronto, Canada

${ }^{\mathrm{f}}$ Knight Cardiovascular Institute, Oregon Health \& Science University, Portand, OR, USA

${ }^{\mathrm{g}}$ Center for Congenital Heart Disease, Inselspital - Bern University Hospital, University of Bern, Bern, Switzerland,

${ }^{\mathrm{h}}$ Division of Congenital and Structural Cardiology, University Hospitals Leuven, Leuven, Belgium

${ }^{\mathrm{i}}$ KU Leuven Department of Cardiovascular Sciences, KU Leuven - University of Leuven, Leuven, Belgium

${ }^{\mathrm{j}}$ Department of Adult Congenital Heart Disease, Chiba Cardiovascular Center, Chiba, Japan

${ }^{\mathrm{k}}$ Department of Cardiology, Academic Medical Center, Amsterdam, the Netherlands

${ }^{1}$ School of Nursing, College of Medicine, National Taiwan University, Taipei, Taiwan

${ }^{\mathrm{m}}$ Center for Biobehavioral Health, Nationwide Children's Hospital, Columbus, OH, USA

${ }^{\mathrm{n}}$ Adult Congenital Heart Center, Montreal Heart Institute, Université de Montréal, Montreal, Canada

${ }^{o}$ Pediatric Cardiology, Frontier Lifeline Hospital (Dr. K. M. Cherian Heart Foundation), Chennai, India

${ }^{\mathrm{p}}$ Division of Cardiology, Hospital de Niños, Córdoba, Argentina

${ }^{\mathrm{q}}$ Adult Congenital Heart Disease Center, Oslo University Hospital - Rikshospitalet, Oslo, Norway

${ }^{\mathrm{r}}$ Adult Congenital Heart Unit, Sahlgrenska University Hospital/Östra, Gothenburg, Sweden

${ }^{\mathrm{s}}$ Institute of Medicine, The Sahlgrenska Academy at University of Gothenburg, Sweden

${ }^{t}$ Department of Health Sciences, University West, Trollhättan, Sweden

u Department of Public Health and Clinical Medicine, Umeå University, Umeå, Sweden 
v Division of Cardiology, Stollery Children's Hospital, University of Alberta, Edmonton, Canada,

${ }^{\mathrm{w}}$ Monash Heart, Monash Medical Centre, Monash University, Melbourne, Australia

${ }^{x}$ Department of Cardiology, Mater Dei Hospital, Birkirkara Bypass, Malta

${ }^{y}$ Adult Congenital Heart Disease Center, Cincinnati Children's Hospital Medical Center, Cincinnati, $\mathrm{OH}, \mathrm{USA}$

${ }^{\mathrm{z}}$ Department of Congenital Heart Disease, Louis Pradel Hospital, Hospices civils de Lyon, Lyon, France

${ }^{\text {aa }}$ Stanford University School of Medicine, Department of Pediatrics and Medicine, Division of Pediatric Cardology and Cardiovascular Medicine, Palo Alto, CA, USA

${ }^{\mathrm{ab}}$ Adult Congenital Heart Disease Center, Washington University and Barnes Jewish Heart \& Vascular Center, University of Missouri, Saint Louis, MO, USA

${ }^{\text {ac }}$ Clinical Psychology Service, IRCCS Policlinico San Donato, Milan, Italy

${ }^{\text {ad }}$ Adult Congenital Heart Disease Center University of Nebraska Medical Center/ Children's Hospital and Medical Center, Omaha, NE, USA

Address for correspondence: Philip Moons, KU Leuven Department of Public Health and Primary Care, Kapucijnenvoer 35, Box 7001, B-3000 Leuven, Belgium. Tel.: +32 16373315 ; fax: + 3216 336970. E-mail address: Philip.Moons@kuleuven.be

All authors take responsibility for all aspects of the reliability and freedom from bias of the data presented and their discussed interpretation. 


\begin{abstract}
Aims: Religion and spirituality can be resources for internal strength and resilience, and may assist with managing life's challenges. Prior studies have been undertaken primarily in countries with high proportions of religious/spiritual people. We investigated (i) whether being religious/spiritual is an independent predictor of patient-reported outcomes (PROs) in a large international sample of adults with congenital heart disease, (ii) whether the individual level of importance of religion/spirituality is an independent predictor for PROs, and (iii) if these relationships are moderated by the degree to which the respective countries are religious or secular.
\end{abstract}

Methods and Results: APPROACH-IS was a cross-sectional study, in which 4,028 patients from 15 countries were enrolled. Patients completed questionnaires to measure perceived health status; psychological functioning; health behaviors; and quality of life.

Religion/spirituality was measured using three questions: Do you consider yourself religious or spiritual?; How important is religion, spirituality, or faith in your life?; and If religious, to what religion do you belong?. The country level of religiosity/secularity was appraised using data from the Gallup Poll 2005-2009. General linear mixed models, adjusting for patient characteristics and country differences were applied. Overall, $49.2 \%$ of patients considered themselves to be religious/spiritual. Being religious/spiritual and considering religion/spirituality as important in one's life was positively associated with quality of life, satisfaction with life and health behaviors. However, among patients living in more secular countries, religion/spirituality was negatively associated with physical and mental health. Conclusion: Religiosity/spirituality is an independent predictor for some PROs, but has differential impact across countries. 
Keywords: cross-cultural comparison; religion; heart defects, congenital; patient-reported outcomes 


\section{Introduction}

In a 2017 editorial in the Journal of the American Medical Association, Tyler VanderWeele and colleagues contended that "Modern day clinicians regularly overlook dimensions of spirituality when considering the health of others or even themselves”.(1) Religion or spirituality can be resources for internal strength and resilience. Indeed, some people look for strength and solace through a deeper connection with a universal spirit, and can find this by being part of religious communities and practices.(1) Research has found that religion/spirituality is associated with better mental health,(2) better self-management among patients with chronic diseases,(3) and higher levels of happiness.(4) In other words, religion/spirituality is an important social determinant of health.(5) However, most prior studies have been undertaken in countries with a high proportion of people who are religious or spiritual, and where religion/spirituality has an important place in society, such as the United States of America, United Kingdom, Kuwait or Iran.(4) In more secular countries, the impact of religion/spirituality seems to be different than in highly religious countries.(3) Hence, to attain a better understanding of the relationship between religion/spirituality and health outcomes, this association needs to be investigated in international samples, including patients coming from both religious and more secular countries. $(6,7)$ In the present study, we investigated (i) if being religious/spiritual is an independent predictor of patient-reported outcomes (PROs) in a large international sample of adults with congenital heart disease (CHD), (ii) whether the individual level of importance of religion/spirituality, in other words the centrality of religion/spirituality in one's life, is an independent predictor for PROs, and (iii) if these relationships are moderated by the general level of religiosity/secularity in the respective countries. 


\section{Methods}

\subsection{Design and setting}

The present study is part of the "Assessment of Patterns of Patient-Reported Outcomes in Adults with Congenital Heart disease - International Study" (APPROACH-IS), which is a cross-sectional, observational study in 15 countries from 5 continents: Argentina, Australia, Belgium, Canada, France, India, Italy, Japan, Malta, Norway, Sweden, Switzerland, Taiwan, the Netherlands, and the United States of America (USA).(8) The study was carried out in accordance with the Code of Ethics of the World Medical Association (Declaration of Helsinki) for experiments involving humans and was approved by the institutional review board of the University Hospitals Leuven/KU Leuven, Belgium (the coordinating center) as well as the local institutional review boards of participating centers when required. All participants provided written informed consent. The rationale, design, and methods of APPROACH-IS have been detailed in a related methods paper.(8)

\subsection{Study population}

Patients were eligible to participate if they met the following inclusion criteria: (i) diagnosis of CHD, defined as a structural abnormality of the heart or intra-thoracic great vessels that is present at birth and actually or potentially of functional significance;(9) (ii) 18 years of age or older; (iii) diagnosis established before adolescence; (iv) continued follow-up at a CHD center or included in a national/regional registry; and (v) physical, cognitive, and language capabilities required to complete self-report questionnaires. Patients were ineligible if they had: (i) prior heart transplantation or (ii) primary pulmonary hypertension.(8) Patients who met the inclusion criteria were mailed a package comprised of the questionnaires or were given them during an outpatient clinic visit. Data were collected from April 2013 through March 2015. 


\subsection{Variables and measurement}

The set of self-report questionnaires was constructed to assess four PRO domains: (i) perceived health status using the 12-item Short Form Health Survey(10) and the EuroQOL5D Visual Analog Scale;(11) (ii) psychological functioning using the Hospital Anxiety and Depression Scale;(12) (iii) health behaviors (i.e., dental hygiene, sports participation, the use of alcohol, tobacco, and/or drugs) using the Health Behavior Scale-Congenital Heart Disease;(13) and (iv) quality of life using a Linear Analog Scale;(14) and the Satisfaction With Life Scale.(15) Expanded definitions of the domains as applied in APPROACH-IS as well as the interpretation of scores for the individual questionnaires have been provided previously.(16) Details on the questionnaires, the translations and the psychometric properties are provided in the APPROACH-IS methods paper.(8)

Religion/spirituality was measured using three questions: 1. "Do you consider yourself religious or spiritual?" (yes/no); 2. “On a scale from 0 to 10 , how important is religion, spirituality, or faith in your life?" $(0=$ not important; $10=$ very important $)$; and 3. "If religious, to what religion do you belong?" No a priori definitions of religion/spirituality were provided to the patients.

To appraise the degree to which the 15 participating countries were religious or secular, we used data from the Gallup World Poll 2005-2009. The Gallup World Poll is a continual cross-sectional survey of the adult population in more than 150 countries, using randomly selected, nationally representative samples comprising about 1000 persons per country.(17) From 2005 to 2009, the Gallup World Poll sampled 455,104 persons from 154 nations.(18) All samples are nationally representative of the population aged 15 years or older.(18) Surveyed persons were asked "Is religion an important part of your daily life?" (yes/no).(18) The proportion of people in the general population who indicated that religion 
was important in their daily life as found in the Gallup Poll 2005-2009 is provided in Online Table 1.

\subsection{Statistical analyses}

Continuous PRO data are presented as means and standard deviations if normally distributed, and as medians and interquartile ranges (IQR) if not normally distributed. Categorical variables are presented as absolute numbers and percentages. Univariable twogroup analyses (e.g., being religious/spiritual or not) were performed using Student's t-test. Bivariate correlations were tested by calculating Spearman's correlation coefficient.

To investigate whether religion/spirituality was an independent predictor of PROs, we computed multivariable General Linear Mixed Models (GLMM), adjusting for age, sex, marital status, educational level, employment status, disease complexity, NYHA class (fixed effects), and for unmeasured country differences (random effect). Furthermore, we evaluated if the country's level of religiosity/secularity (Gallup Poll) moderates the relationship between religion/spirituality and PROs by adding the Gallup data as an interaction term in the GLMM (Gallup * religion/spirituality). Simple slope analysis allowed us to identify secular, moderately religious and highly religious countries. Data analysis was performed using IBM SPSS Statistics for Windows, version 25 (Armonk, NY: IBM Corp.). Tests were two-tailed and $p<0.05$ was used as level of significance. In order to calculate the magnitude of the difference between religious and non-religious patients, we calculated effect sizes. For continuous variables, an effect size for the Wilcoxon test was calculated by $r=Z / \sqrt{ }$, where $Z$ is the normal approximation of the Wilcoxon test statistic - that is the Mann-Whitney U. For categorical variables, Cohen's w was calculated. The cut-offs for Cohen's w and r were as follows: $0.1-0.3=$ small difference; $0.3-0.5=$ moderate difference; and $>0.5=$ large difference. 


\section{Results}

\subsection{Self-identification as religious/spiritual}

In APPROACH-IS, 4028 patients were enrolled, with a median age of 32 years and 53\% were women.(16, 19) Overall, 49.2\% (1936 out of 3934) of the patients considered themselves to be religious or spiritual. These patients were more likely be female, slightly older, in worse functional classes, and had a slight tendency to higher education compared to those who were not religious or spiritual (Table 1). For sex and functional class, the difference between the two groups was large. There was no significant differences between the 2 groups regarding complexity of the heart defect.

A large inter-country variation was observed in the proportion of patients who considered themselves religious or spiritual. Countries with the highest proportions of religious/spiritual patients were Argentina (84.4\%), Malta (84.3\%), USA (76.8\%) and India (72.4\%) (Figure 1, panel A). Lower proportions of patients who considered themselves religious/spiritual were found in Japan (18.9\%), Sweden (26.2\%), France (30.8\%) and Norway (31.8\%). The distribution of the religions in included patients across the 15 countries is presented in Online Table 2.

\subsection{Centrality of religion/spirituality in one's life}

Among patients who considered themselves religious or spiritual, variation in the level of importance of religion, spirituality or faith in their life was observed (Figure 1, panel B). On a scale from 0 to 10 , a large majority ( $85 \%)$ of religious/spiritual patients selected a score of 5 or higher; further, $29 \%$ chose the highest score of 10 (Figure 1, panel B). The mean religion/spirituality importance scores by country are shown in Online Table 2, demonstrating that religion/spirituality/faith was most important to patients from Argentina (6.7), Malta 
(6.6) and the United States (6.2). Patients from Japan (1.0), Sweden (1.6) and Norway (1.7) considered religion/spirituality less important in their lives.

\subsection{Religion/spirituality as predictor of PROs and moderating effects of country level}

Univariable analyses indicated that patients who considered themselves religious or spiritual had lower levels of physical (PCS) and mental health (MCS), worse self-rated health status (EQ-VAS), more anxiety (HADS-A), but higher satisfaction with life (SWLS) (Online Table 3). When looking at the level of importance that patients assigned to religion/spirituality in their life, we found that the more important religion/spirituality was for patients, the lower the levels of physical (PCS) and mental health (MCS), the more anxiety (HADS-A), but the better the quality of life (LAS QOL) and satisfaction with life (SWLS) (Online Table 4).

Multivariable GLMM, adjusting for patient characteristics and unmeasured country differences, revealed that being religious/spiritual was a predictor for better health behaviors, better quality of life (LAS QOL), and a higher satisfaction with life (SWLS) (Table 2). Health behaviors, however, were also predicted by country level of religion/spirituality (Gallup Poll), such that patients living in secular countries generally showed better health behaviors than patients from religious countries. A significant interaction effect was found for mental health (MCS) (Table 2), indicating that the relationship between being religious/spiritual and mental health was moderated by the country level of religiosity/secularity. More specifically, among patients living in secular or moderately religious countries, mental health was better in those who were not religious/spiritual compared to those who were religious/spiritual (Online Figure 1, panel A). In highly religious countries, no difference in mental health was found among religious versus non-religious patients. 
Higher patient scores for the importance of religion/spirituality in their lives, when adjusted for patient characteristics and unmeasured country differences, predicted lower physical health (PCS), more anxiety (HADS-A), better health behaviors, better quality of life (LAS QOL), and higher satisfaction with life (SWLS) (Table 3). Also in these analyses, health behaviors were better in patients from more secular countries. Interaction effects were found for physical (PCS) and mental health (MCS), and for depression (HADS-D). More specifically, the negative relationship between the importance of religion/spirituality and physical and mental health was only observed in patients living in secular and moderately religious countries, and not in those from highly religious countries (Online Figure 1, Panel $\mathrm{B}, \mathrm{C}$ and D).

\section{Discussion}

The relationship between religion/spirituality and health outcomes remains poorly understood. This may reflect the fact that studies on the differential impact of religion/spirituality across different countries or cultures are scarce.(6) Within the field of cardiology, to the best of our knowledge, published studies do not exist. Since APPROACHIS investigated PROs in adults with CHD from 15 countries in 5 continents using a uniform methodology, the APPROACH-IS dataset provides a unique opportunity to scrutinize the relationship between religion/spirituality and PROs across countries. Our analyses indicate that religion/spirituality is associated with both positive and negative health outcomes above and beyond patient characteristics, yet also that it sometimes depends on the general level of religion/spirituality among citizens in the respective countries. More specifically, patients who are religious or spiritual and who consider religion/spirituality important to their lives seem to have a better quality of life and higher satisfaction with life, independent of their country or their individual characteristics. Religion/spirituality was also a positive predictor 
for healthy behaviors, although health behaviors were overall better in more secular countries. A negative association between religion/spirituality and physical and mental health, including anxiety and depression, was identified. The association with depression, however, it was only found in secular and moderately religious countries as opposed to highly religious countries. This finding indicates that the relationships between religion/spirituality and PROs are complex and, in part, moderated by the general level of religiousness in countries. The relationship between religiosity and negative feelings, and variation according to country of residence, has previously been noted.(18)

A positive relationship between religion/spirituality and quality of life has previously been reported. $(4,18,20)$ Although a worldwide study found that there is a differential relationship between religion and well-being in countries with good life circumstances compared to those countries that are worse of,(18) a recent meta-analysis did not confirm that this relationship was dependent upon the country of residence.(4) Furthermore, studies have found a beneficial effect of religious and spiritual interventions, such as praying in groups or meditation, as a complementary therapy in terms of quality of life.(21) The fact that the association between religion/spirituality and quality of life and satisfaction with life was not only found for a dichotomous assessment of being religious/spiritual, but also for the extent to which patients consider religion/spirituality important in their lives, suggests that there may be a certain "dose-response" relationship. $(1,5)$

A recent literature review outlined vast evidence for the positive relationship between religion/spirituality and health behaviors,(22) which the present findings have confirmed. However, those results should be interpreted in light of our finding that better health behaviors are generally more common in more secular countries. Hence, it could be assumed that the potential benefit of religion/spirituality with respect to health behaviors is more pronounced in religious countries than in secular countries, although no interaction effect was 
detected in the present study. One possible mechanism to account for the relationship between religion/spirituality and health behaviors is that being religious promotes formal participation in religious communities and practices, which in turn may enhance social integration that fosters healthy behaviors and provides social support. $(1,5)$ Positive health behaviors are believed to be the mediating factor for why religion/spirituality and its practices are associated with a lower mortality.(5, 23) Nonetheless, it may seem counterintuitive that religion/spirituality was positively associated with health behaviors and negatively related with physical functioning. Based on this observation, one might presume that health behaviors and physical functioning are inversely related. However, previous APPROACH-IS analyses indicated this was not the case.(16) This observation thus highlights the complex relationships between religiosity/spirituality with PROs that would benefit from future mixed-methods inquiry to understand.

In the present study, we found a negative relationship between religion/spirituality and physical and mental health. With the exception of anxiety, this relationship was moderated by the religiosity/secularity level of the country, such that this negative relationship was only found for patients in secular countries and not in religious countries. A similar observation was made in another international cohort study, where people who held a religious or spiritual understanding of life had a higher incidence of depression, but the relationship varied by country.(6) Our study expands on such findings(6) by identifying a moderating effect of the religiosity/secularity level in the country as a whole on the relationship between individual religion/spirituality level and mental health.

\subsection{Methodological considerations}

With this study, we contributed to the current body of knowledge by investigating the differential impact of religion/spirituality on PROs. We relied on a sound research 
methodology and conceptualization of PROs. $(8,24)$ Nonetheless, our findings should be interpreted in light of certain limitations. $(8,16,19)$ First, APPROACH-IS is a cross-sectional study, and thus causality between religion/spirituality and PROs or the directionality of the associations could not be determined.(8) Indeed, it could be that the relationship is bidirectional, given that it is plausible that physical and mental health influence religion/spirituality pursuits.(25) More precisely, patients who are experiencing significant health problems may be more likely to actively seek solace in religion/spirituality. Indeed, a large-scale study in more than 400,000 individuals around the globe found that people living in difficult circumstances, both at individual and country level, had greater religiosity.(18) Future studies should look more into the direction of effect and causality. Second, for most participating countries, data from only one center was available. This limitation might hamper the representativeness of our sample.(16, 19) Third, a possible selection bias cannot be excluded, because patients who were physically or mentally incapable of completing the questionnaires were not represented in this study.(8) However, in the Swedish branch of APPROACH-IS, participants and non-participants were compared and only minor differences in demographic and clinical data were observed.(26) Fourth, due to the unbalanced distribution of religions within the APPROACH-IS sample (see Online Table 2), we were not able to properly investigate the differential impact on PROs of affiliating with a religion vs. considering oneself to be spiritual. For such a study, a more equal distribution of the religions over all participating countries and separate questions regarding religiosity and spirituality would be needed. Most study participants identified with the Christian religion. As each religion has its own unique characteristics and perspectives (e.g., consideration of an afterlife), larger samples with purposeful sampling of other religions (e.g., Hinduism, Buddhism, Islam) are recommended. Such a study would also allow us to investigate what the illness perceptions are of people belonging to different religions.(27) Fifth, demographic 
and clinical differences were found between the cohort of patients that considered themselves to be religious/spiritual or not. However, by adjusting for patient factors in the GLMM, we accounted for these baseline differences. Sixth, we investigated the predictive role of being religious/spiritual and the level of importance that religion/spirituality has in one's life in different statistical models. It would have been interesting to assess whether PROs are predicted to greater extent by being religious or by the importance of religion/spirituality to the individual. However, due to multicollinearity between these two factors (Variance Inflaction Factor $>5$ ), we could not enter them into the same GLMM. Seventh, although we found evidence for a differential impact of religion/spirituality on PROs according to countries' general level of religiosity, we do not know the precise mechanism underlying this phenomenon. For example, we do not know whether there are unique characteristics of individuals who seek religious affiliation in a country in which it is less common. Eighth, we used the Gallup Poll 2005-2009 data to appraise the degree to which the participating countries were religious or secular, instead of the more recent 2015 Poll because the older version included three APPROACH-IS countries (Malta, Norway, Taiwan) that were not included in the later version. It should also be noted that the intraclass correlation between the 2005-2009 and 2015 versions was 0.964 .

The relationship between religion/spirituality and health outcomes is complex and warrant future research. In this study, religion/spirituality was assessed using three questions. Future mixed-methods research is encouraged to investigate the psychosocial dimensions of religiosity/spirituality in more depth and the potentially complex relationship with quality of life. When the precise interrelationship is understood and the direction of effect is known, religious and spiritual interventions may find their way to healthcare. $(21,28)$ Spiritual care could become a service that is structurally offered to adults with congenital heart disease.(29) 
However, before implementing such interventions, the differential effect in the different countries should be beared in mind.

\section{Conclusion}

Self-identification as religious/spiritiual and attributing a higher importance of religion/spirituality in one's life was positively associated with quality of life, satisfaction with life and health behaviors. However, among patients living in more secular countries, religion/spirituality was negatively associated with physical and mental health. Hence, the present study highlighted the differential impact that religion/spirituality may have on health outcomes in various countries. Furthermore, our findings suggest that international studies ought to consider religion/spirituality when assessing potential predictors of PROs.

Funding: This work was supported by the Research Fund - KU Leuven (Leuven, Belgium) through grant OT/11/033 to K.L. and P.M.; by the Swedish Heart-Lung Foundation (Sweden) through grant number 20130607 to M.D.; by the University of Gothenburg Centre for Person-centred Care (Gothenburg, Sweden) to M.D. and P.M.; and by the Cardiac Children's Foundation (Taiwan) through grant CCF2013_02 to H.L.Y. Furthermore, this work was endorsed by and conducted in collaboration with the International Society for Adult Congenital Heart Disease.

Acknowledgements: We wish to thank the APPROACH-IS participants who made this study possible. In addition, we would like to thank all individuals at the participating centers who made substantial contributions to APPROACH-IS. 
Conflict of Interest: None of the authors have a conflict of interest

Registration: ClinicalTrials.gov: NCT02150603.

\section{Collaborators}

APPROACH-IS consortium: Luis Alday, Héctor Maisuls, Betina Vega (Córdoba, Argentina, Hospital de Niños); Samuel Menahem, Sarah Eaton, Qi Feng Wang, Ruth Larion (Melbourne, Australia, Monash Medical Center); Werner Budts, Kristien Van Deyk (Leuven, Belgium, University Hospitals of Leuven); Silke Apers, Eva Goossens, Jessica Rassart, Koen Luyckx, Philip Moons (Leuven, Belgium, University of Leuven); Gwen Rempel, Andrew Mackie, Ross Ballantyne, Kathryn Rankin, Colleen Norris, Dylan Taylor, Isabelle Vondermuhll, Jonathan Windram, Pamela Heggie, Gerri Lasiuk (Edmonton, Canada, University of Alberta); Paul Khairy, Anna Proietti, Annie Dore, Lise-Andrée Mercier, François-Pierre Mongeon, François Marcotte, Reda Ibrahim, Blandine Mondésert, MarieClaude Côté (Montreal, Canada, Montreal Heart Institute); Adrienne Kovacs, Erwin Oechslin, Mimi Bandyopadhyay (Toronto, Canada, University Health Network); Alexandra Soufi, Sylvie Di Filippo, François Sassolas, André Bozio, Cécile Chareyras (Lyon, France, Louis Pradel Hospital); Shanthi Chidambarathanu, Farida Farzana, Nitya Lakshmi (Chennai, India, Frontier Lifeline Hospital, Dr. K. M. Cherian Heart Foundation); Edward Callus, Emilia Quadri, Massimo Chessa, Giovanna Campioni, Alessandro Giamberti (Milan, Italy, IRCCS Policlinco San Donato Hospital); Junko Enomoto, Yoshiko Mizuno (Chiba, Japan, Chiba Cardiovascular Center); Maryanne Caruana, Victor Grech, Sheena Vella, Anabel Mifsud, Neville Borg, Daniel Chircop, Matthew Mercieca Balbi, Rachel Vella Critien, James Farrugia, Yanika Gatt, Darlene Muscat (Msida, Malta, Mater Dei Hospital); Katrine Eriksen, 
Mette-Elise Estensen (Oslo, Norway, Oslo University Hospital); Mikael Dellborg, Malin Berghammer (Gothenburg, Sweden, Sahlgrenska University Hospital); Eva Mattsson, Anita Strandberg, Pia Karlström-Hallberg (Stockholm, Sweden, Karolinska University Hospital); Bengt Johansson, Anna-Karin Kronhamn (Umeå, Sweden, University Hospital of Umeå); Markus Schwerzman, Corina Thomet, Margrit Huber (Bern, Switzerland, University Hospital Bern); Jou-Kou Wang, Chun-Wei Lu, Hsiao-Ling Yang, Yu Chuan Hua (Taipei, Taiwan, National Taiwan University Hospital); Barbara Mulder, Maayke Sluman (Amsterdam, the Netherlands, Amsterdam Medical Center); Marco Post (Nieuwegein, the Netherlands, St. Antonius Hospital); Els Pieper (Groningen, the Netherlands, University Medical Center Groningen); Kathinka Peels (Eindhoven, the Netherlands, Catharina Hospital); Marc Waskowsky (Zwolle, the Netherlands, Isala Clinic); Gruschen Veldtman, Michelle Faust, Colin Lozier, Christy Reed, Jamie Hilfer (Cincinnati, USA, Cincinnati Children's Hospital Medical Center); Curt Daniels, Jamie Jackson (Columbus, USA, Nationwide Children's Hospital); Shelby Kutty, Carolyn Chamberlain, Sara Warta (Omaha, USA, Children's Hospital \& Medical Center); Stephen Cook, Morgan Hindes (Pittsburgh, USA, Children's Hospital of Pittsburgh of UPMC); Ari Cedars, Kamila White (Saint Louis, USA, Washington University and Barnes Jewish Heart \& Vascular Center, University of Missouri); Susan Fernandes, Anitra Romfh, Kirstie MacMillen (Palo Alto, USA, Stanford University). 


\section{References}

1. VanderWeele TJ, Balboni TA, Koh HK. Health and Spirituality. JAMA. 2017;318(6):519-20 .

2. AbdAleati NS, Mohd Zaharim N, Mydin YO. Religiousness and Mental Health: Systematic Review Study. J Relig Health. 2016;55(6):1929-37.

3. Janssen-Niemeijer AJ, Visse M, Van Leeuwen R, Leget C, Cusveller BS. The Role of Spirituality in Lifestyle Changing Among Patients with Chronic Cardiovascular Diseases: A Literature Review of Qualitative Studies. J Relig Health. 2017;56(4):1460-77.

4. Rizvi MAK, Hossain MZ. Relationship Between Religious Belief and Happiness: A Systematic Literature Review. J Relig Health. 2017;56(5):1561-82.

5. Idler E, Blevins J, Kiser M, Hogue C. Religion, a social determinant of mortality? A 10-year follow-up of the Health and Retirement Study. PLoS One. 2017;12(12):e0189134.

6. Leurent B, Nazareth I, Bellon-Saameno J, Geerlings MI, Maaroos H, Saldivia S, et al. Spiritual and religious beliefs as risk factors for the onset of major depression: an international cohort study. Psychol Med. 2013;43(10):2109-20.

7. la Cour P, Avlund K, Schultz-Larsen K. Religion and survival in a secular region. A twenty year follow-up of 734 Danish adults born in 1914. Soc Sci Med. 2006;62(1):157-64.

8. Apers S, Kovacs AH, Luyckx K, Alday L, Berghammer M, Budts W, et al. Assessment of Patterns of Patient-Reported Outcomes in Adults with Congenital Heart disease International Study (APPROACH-IS): rationale, design, and methods. Int J Cardiol. $2015 ; 179: 334-42$.

9. Mitchell SC, Korones SB, Berendes HW. Congenital heart disease in 56,109 births. Incidence and natural history. Circulation. 1971;43(3):323-32. 
10. Ware JE, Kosinski M, Turner-Bowker DM, Sundaram M, Gandek B, Maruish ME. User's Manual for the SF-12v2 Health Survey Second Edition: QualityMetric, Incorporated; 2009.

11. EuroQol Group. EuroQol--a new facility for the measurement of health-related quality of life. Health Policy. 1990;16(3):199-208.

12. Zigmond AS, Snaith RP. The hospital anxiety and depression scale. Acta Psychiatr Scand. 1983;67(6):361-70.

13. Goossens E, Luyckx K, Mommen N, Gewillig M, Budts W, Zupancic N, et al. Health risk behaviors in adolescents and emerging adults with congenital heart disease: psychometric properties of the Health Behavior Scale-Congenital Heart Disease. Eur J Cardiovasc Nurs. 2013;12(6):544-57.

14. Moons P, Van Deyk K, De Bleser L, Marquet K, Raes E, De Geest S, et al. Quality of life and health status in adults with congenital heart disease: a direct comparison with healthy counterparts. Eur J Cardiovasc Prev Rehabil. 2006;13(3):407-13.

15. Diener E, Emmons RA, Larsen RJ, Griffin S. The Satisfaction with Life Scale. J Pers Assess. 1985;49(1):71-5.

16. Moons P, Kovacs AH, Luyckx K, Thomet C, Budts W, Enomoto J, et al. Patientreported outcomes in adults with congenital heart disease: Inter-country variation, standard of living and healthcare system factors. Int J Cardiol. 2018;251:34-41.

17. Gallup. Worldwide Research Methodology and Codebook. New York: Gallup Inc.; 2011.

18. Diener E, Tay L, Myers DG. The religion paradox: if religion makes people happy, why are so many dropping out? J Pers Soc Psychol. 2011;101(6):1278-90. 
19. Apers S, Kovacs AH, Luyckx K, Thomet C, Budts W, Enomoto J, et al. Quality of Life of Adults With Congenital Heart Disease in 15 Countries: Evaluating Country-Specific Characteristics. J Am Coll Cardiol. 2016;67(19):2237-45.

20. Koenig HG. Religion, spirituality, and health: a review and update. Adv Mind Body Med. 2015;29(3):19-26.

21. Goncalves JPB, Lucchetti G, Menezes PR, Vallada H. Complementary religious and spiritual interventions in physical health and quality of life: A systematic review of randomized controlled clinical trials. PLoS One. 2017;12(10):e0186539.

22. Park CL, Masters KS, Salsman JM, Wachholtz A, Clements AD, Salmoirago-Blotcher E, et al. Advancing our understanding of religion and spirituality in the context of behavioral medicine. J Behav Med. 2017;40(1):39-51.

23. Koenig LB, Vaillant GE. A prospective study of church attendance and health over the lifespan. Health Psychol. 2009;28(1):117-24.

24. Bratt EL, Moons P. Forty years of quality-of-life research in congenital heart disease: Temporal trends in conceptual and methodological rigor. Int J Cardiol. 2015;195:1-6.

25. Pargament KI, Koenig HG, Tarakeshwar N, Hahn J. Religious struggle as a predictor of mortality among medically ill elderly patients: a 2-year longitudinal study. Arch Intern Med. $2001 ; 161(15): 1881-5$.

26. Berghammer MC, Mattsson E, Johansson B, Moons P, Dellborg M. Comparison of participants and non-participants in patient-reported outcome surveys: the case of Assessment of Patterns of Patient-Reported Outcomes in Adults with Congenital Heart disease International Study. Cardiol Young. 2017;27(3):427-34.

27. Rassart J, Apers S, Kovacs AH, Moons P, Thomet C, Budts W, et al. Illness perceptions in adult congenital heart disease: A multi-center international study. Int $\mathrm{J}$ Cardiol. 2017;244:130-8. 
28. Hook JN, Worthington EL, Jr., Davis DE, Jennings DJ, 2nd, Gartner AL, Hook JP. Empirically supported religious and spiritual therapies. J Clin Psychol. 2010;66(1):46-72.

29. Moons P, Meijboom FJ, Baumgartner H, Trindade PT, Huyghe E, Kaemmerer H, et al. Structure and activities of adult congenital heart disease programmes in Europe. Eur Heart J. 2010;31(11):1305-10. 


\section{Figure legends}

FIGURE 1. The level of religiosity/spirituality in patients with congenital heart disease from 15 countries 
TABLE 1. Demographic and medical background variables in adults with congenital heart disease according to self-identification as religious/spiritual

\begin{tabular}{|c|c|c|c|c|}
\hline Variables & $\begin{array}{c}\text { Religious/ } \\
\text { Spiritual persons }\end{array}$ & $\begin{array}{l}\text { Non-religious/ Non- } \\
\text { spiritual persons }\end{array}$ & p-value & Effect size \\
\hline Sex: women & $1124 / 1927(58.3 \%)$ & $934 / 1992(46.9 \%)$ & $<0.001^{\S}$ & $w=0.82$ \\
\hline Median age in years & 32 (IQR 25-43) & $31($ IQR 25-40) & $0.004^{\text {ๆ }}$ & $r=-0.0457$ \\
\hline Educational level & & & $0.007^{\S}$ & $w=0.20$ \\
\hline Less than high school & $112 / 1916(5.8 \%)$ & $100 / 1984(5.0 \%)$ & & \\
\hline High school & $777 / 1916(40.6 \%)$ & $880 / 1984(44.4 \%)$ & & \\
\hline College degree & $449 / 1916(23.4 \%)$ & $385 / 1984(19.4 \%)$ & & \\
\hline University degree & $578 / 1916(30.2 \%)$ & $619 / 1984(31.2 \%)$ & & \\
\hline Patient-reported New York Heart Association functioning & & & $<0.001^{\S}$ & $w=0.63$ \\
\hline Class $1^{\mathrm{a}}$ & $951 / 1889(50.3 \%)$ & $1132 / 1969(57.5 \%)$ & & \\
\hline Class II & $674 / 1889(35.7 \%)$ & $671 / 1969(34.1 \%)$ & & \\
\hline Class III & $163 / 1889(8.6 \%)$ & $115 / 1969(5.8 \%)$ & & \\
\hline Class IV ${ }^{\mathrm{b}}$ & $101 / 1889(5.3 \%)$ & $51 / 1969(2.6 \%)$ & & \\
\hline Complexity of heart defect & & & $0.107^{\S}$ & $w=0.07$ \\
\hline Simple & $472 / 1936(24.4 \%)$ & $540 / 1998(27.0 \%)$ & & \\
\hline Moderate & $949 / 1936(49.0 \%)$ & $969 / 1998(48.5 \%)$ & & \\
\hline Complex & $515 / 1936(26.6 \%)$ & $489 / 1998(24.5 \%)$ & & \\
\hline
\end{tabular}

Chi-Square test; "Mann-Whitney U test 
TABLE 2 Multivariable General Linear Mixed Models with self-identification as religious/spiritual as a predictor of PROs, adjusted for patient characteristics and unmeasured country differences and moderated by country level of general religiosity/secularity

\begin{tabular}{|c|c|c|c|c|c|c|c|}
\hline ల్ర & $\stackrel{\mathcal{U}}{\Sigma}$ & 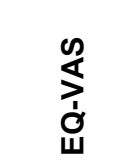 & 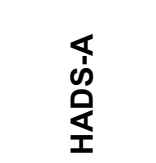 & $\begin{array}{l}\text { 号 } \\
\text { ồ }\end{array}$ & 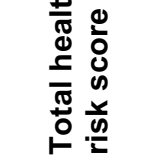 & 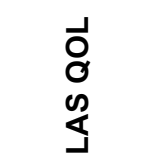 & $\sum_{\infty}^{\infty}$ \\
\hline $9(0.5)$ & $-0.7(0.6)$ & $-0.2(0.5)$ & $0.2(0.1)$ & $-0.07(0.1)$ & $-1.4(0.6)$ & $1.2(0.5)$ & $0.8(0.2)$ \\
\hline \# & \# & \# & \# & \# & \# & \# & \# \\
\hline $1.2(1.0)$ & $0.1(0.6)$ & $0.5(0.5)$ & $0.1(0.2)$ & $0.2(0.2)$ & $3.1(1.1)$ & $0.4(0.7)$ & $0.2(0.3)$ \\
\hline $0.2(0.3)$ & $-0.8(0.3)$ & $-0.3(0.3)$ & $0.04(0.06)$ & $0.04(0.06)$ & $-0.03(0.3)$ & $-0.3(0.3)$ & $-0.1(0.1)$ \\
\hline
\end{tabular}

Values in table are Estimates (SE), adjusted for demographic and medical patient characteristics namely age, sex, marital status, educational level, employment status,

disease complexity, and functional status (NYHA class); \#=reference; PCS=Physical Component Summary; MCS=Mental Component Summary; EQ-VAS=EuroQol 5

Dimensions-Visual Analog Scale; HADS-A=Hospital Anxiety and Depression Scale - Anxiety; HADS-D=Hospital Anxiety and Depression Scale - Depression; LAS

QOL=Linear Analog Scale Quality of Life; SWLS=Satisfaction with Life Scale; For clarity, the demographic and medical predictors are not reported in this table, since they have

been reported in detail previously.(16)

N.S.

$<0.05<0.01<0.001$


TABLE 3 Multivariable General Linear Mixed Models with centrality of religion/spirituality as a predictor of PROs, adjusted for patient characteristics and unmeasured country differences and moderated by country level of general religiosity/secularity

\begin{tabular}{|c|c|c|c|c|c|c|c|}
\hline O্口 & S) & $\begin{array}{l}\infty \\
\text { 文 } \\
\text { ơ }\end{array}$ & 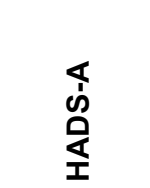 & $\begin{array}{l}\text { ơ } \\
\text { ஹ̊ㅗㅗ }\end{array}$ & 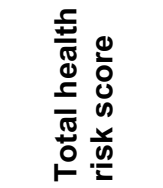 & $\begin{array}{l}\text { वे } \\
\text { o } \\
\text { \& }\end{array}$ & $\sum_{\infty}^{\infty}$ \\
\hline $0.7(0.3)$ & $-0.5(0.3)$ & $0.1(0.3)$ & $0.2(0.07)$ & $-0.02(0.06)$ & $-0.9(0.3)$ & $0.9(0.3)$ & $0.4(0.1)$ \\
\hline $1.3(1.0)$ & $-0.07(0.6)$ & $0.4(0.5)$ & $0.1(0.2)$ & $0.2(0.2)$ & $3.2(1.1)$ & $0.2(0.7)$ & $0.2(0.3)$ \\
\hline $0.6(0.3)$ & $1.5(0.3)$ & $0.5(0.3)$ & $-0.1(0.07)$ & $-0.1(0.06)$ & $0.005(0.3)$ & $0.5(0.3)$ & $0.2(0.1)$ \\
\hline
\end{tabular}

Main effect Importance of religion/spirituality (scale 0-10)

Main effect Country level of religiosity/secularity (Gallup poll)

Moderator Importance of religion/spirituality * country level

Values in table are Estimates (SE), adjusted for demographic and medical patient characteristics namely age, sex, marital status, educational level, employment status, disease complexity, and functional status (NYHA class); PCS=Physical Component Summary; MCS=Mental Component Summary; EQ-VAS=EuroQol 5 Dimensions-Visual Analog Scale; HADS-A=Hospital Anxiety and Depression Scale - Anxiety; HADS-D=Hospital Anxiety and Depression Scale - Depression; LAS QOL=Linear Analog Scale Quality of Life; SWLS=Satisfaction with Life Scale; For clarity, the demographic and medical predictors are not reported in this table, since they have been reported in detail previously.(16) 
FIGURE 1. Religiosity/spirituality in patients with congenital heart disease from 15 countries

Panel A: Proportion of patients with congenital heart disease who consider themselves religious or spiritual

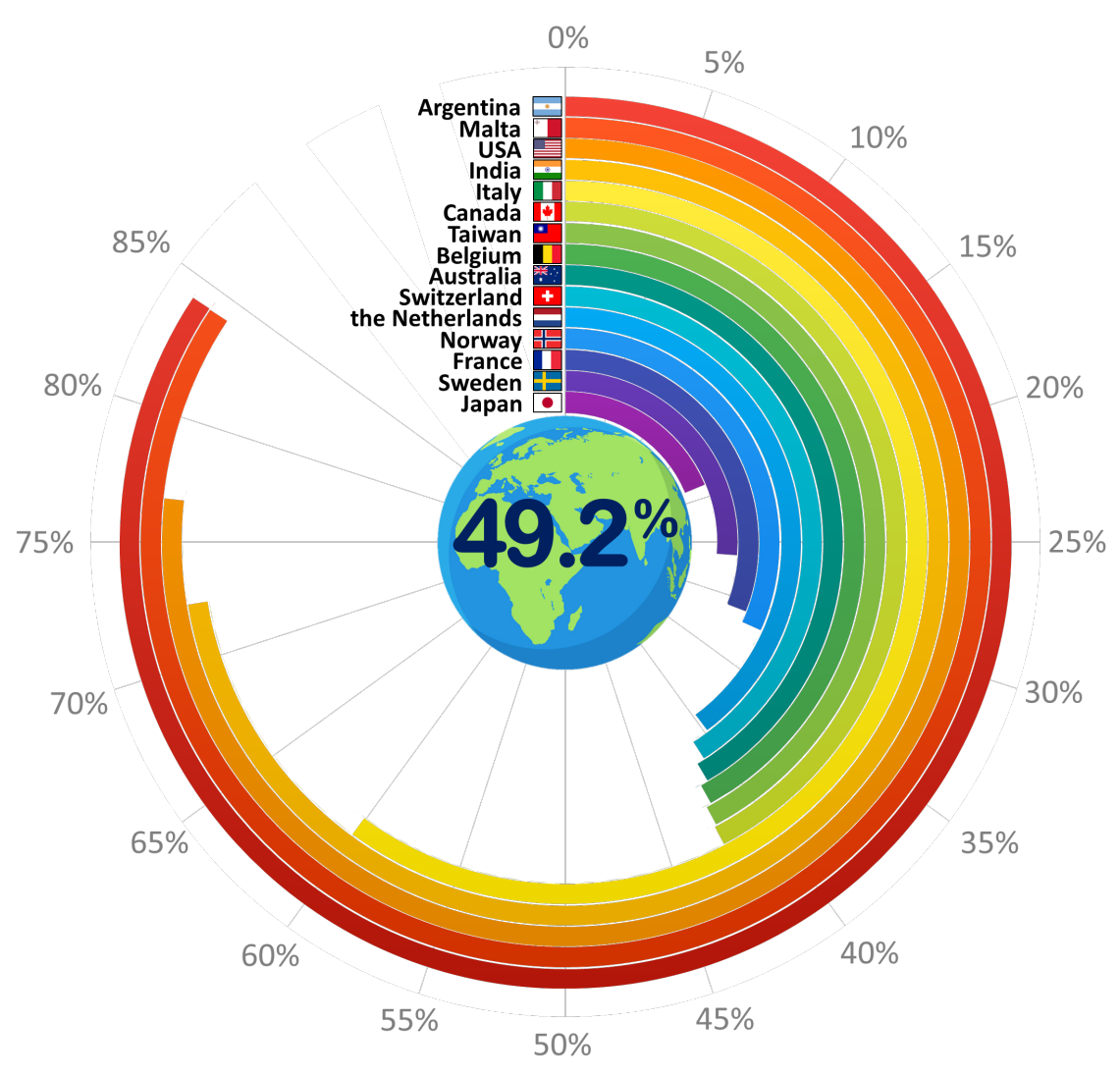

Panel B: The self-reported relative importance of religion, spirituality or faith in the lives of patients with congenital heart disease

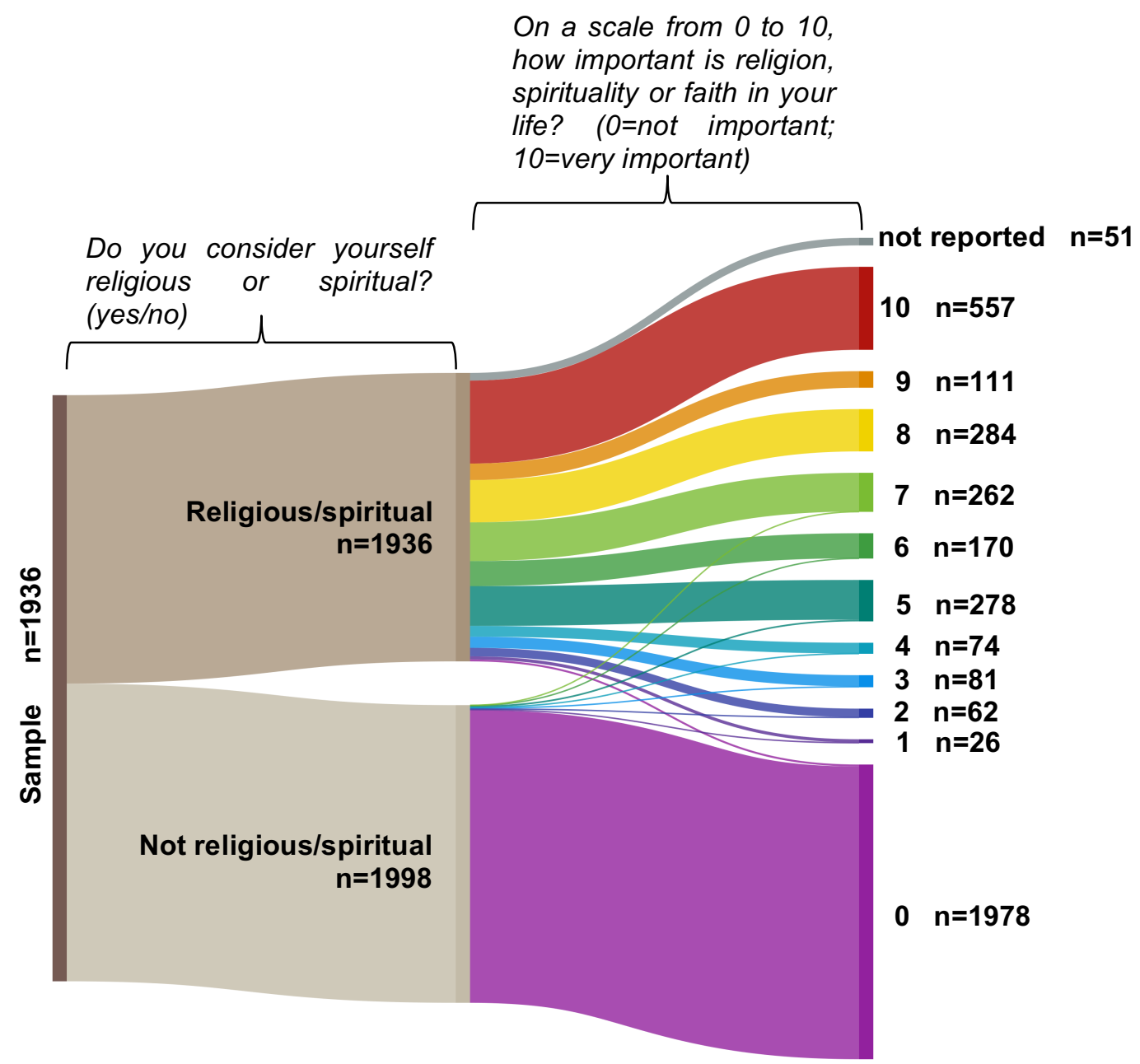


ONLINE TABLE 1: Proportion of people in the general population who indicate that religion is important in their daily life (Gallup Poll 2005-2009)(18)

Gallup 2005-2009

\begin{tabular}{ll}
\hline Argentina & $64 \%$ \\
\hline Australia & $32 \%$ \\
Belgium & $39 \%$ \\
Canada & $45 \%$ \\
France & $27 \%$ \\
India & $85 \%$ \\
Italy & $73 \%$ \\
Japan & $26 \%$ \\
Malta & $90 \%$ \\
Norway & $20 \%$ \\
Sweden & $16 \%$ \\
Switzerland & $43 \%$ \\
Taiwan & $44 \%$ \\
the Netherlands & $33 \%$ \\
USA & $66 \%$ \\
\hline
\end{tabular}


ONLINE TABLE 2: Distribution of religions over the different countries participating in APPROACH-IS

\begin{tabular}{|c|c|c|c|c|c|c|c|c|c|c|}
\hline & $\begin{array}{l}\text { Religious or } \\
\text { spiritual }\end{array}$ & $\begin{array}{c}\text { Mean } \\
\text { religion/spirituality } \\
\text { importance score } \\
\text { (SD) }\end{array}$ & Christianity & Hinduism & Buddhism & Islam & Folk belief & Judaism & Taoism & $\begin{array}{l}\text { Other or not } \\
\text { reported }\end{array}$ \\
\hline Argentina & 146/173 (84.4\%) & $6.7(3.4)$ & $127 / 146(87.0 \%)$ & & & $2 / 146(1.4 \%)$ & & $1 / 146(0.7 \%)$ & & $16 / 146(11.0 \%)$ \\
\hline Australia & $54 / 130(41.5 \%)$ & $3.3(3.6)$ & $41 / 54(75.9 \%)$ & $1 / 54(1.9 \%)$ & $2 / 54(3.7 \%)$ & $1 / 54(1.9 \%)$ & & $3 / 54(5.6 \%)$ & & $6 / 54(11.2 \%)$ \\
\hline Belgium & $108 / 258(41.9 \%)$ & $2.3(3.2)$ & $94 / 108(87.0 \%)$ & & $1 / 108(0.9 \%)$ & $8 / 108(7.4 \%)$ & & & & $5 / 108(4.6 \%)$ \\
\hline Canada & $218 / 515(42.4 \%)$ & $2.8(3.7)$ & $170 / 218(78.0 \%)$ & $3 / 218(1.4 \%)$ & $1 / 218(0.5 \%)$ & $6 / 218(2.8 \%)$ & & $3 / 218(1.4 \%)$ & $1 / 218(0.5 \%)$ & $34 / 218(15.6 \%)$ \\
\hline France & $28 / 91(30.8 \%)$ & $2.1(3.5)$ & $14 / 28(50.0 \%)$ & & & $10 / 28(35.7 \%)$ & & $1 / 28(3.6 \%)$ & & $3 / 28(10.7 \%)$ \\
\hline India & $142 / 196(72.4 \%)$ & $5.7(4.1)$ & $20 / 142(14.1 \%)$ & $94 / 142(66.2 \%)$ & & $21 / 142(14.8 \%)$ & & & & $7 / 142(4.9 \%)$ \\
\hline Italy & $39 / 65(60.0 \%)$ & $4.7(4.2)$ & $37 / 39(94.9 \%)$ & & & & & & & $2 / 39(5.1 \%)$ \\
\hline Japan & $48 / 254(18.9 \%)$ & $1.0(2.3)$ & $2 / 48(4.2 \%)$ & & $14 / 48(29.2 \%)$ & & & & & $32 / 48(66.7 \%)$ \\
\hline Malta & $97 / 115(84.3 \%)$ & $6.6(3.4)$ & $94 / 97(96.9 \%)$ & & & & & & & $3 / 97(3.1 \%)$ \\
\hline Norway & $54 / 170(31.8 \%)$ & $1.7(2.8)$ & $47 / 54(87.0 \%)$ & & & $1 / 54(1.9 \%)$ & & & & $6 / 54(11.2 \%)$ \\
\hline Sweden & $123 / 469(26.2 \%)$ & $1.6(3.1)$ & $96 / 123(78.0 \%)$ & & & $6 / 123(4.9 \%)$ & & 2/123 (1.6\%) & & $19 / 123(15.5 \%)$ \\
\hline Switzerland & $110 / 268(41.0 \%)$ & $2.6(3.6)$ & $88 / 110(80.0 \%)$ & $1 / 110(0.9 \%)$ & $1 / 110(0.9 \%)$ & $5 / 110(4.5 \%)$ & & & & $15 / 110(13.6 \%)$ \\
\hline Taiwan & $107 / 250(42.8 \%)$ & $2.9(3.7)$ & $10 / 107(9.3 \%)$ & & $39 / 107(36.4 \%)$ & & $30 / 107(28.0 \%)$ & & 14/107 (13.1\%) & $14 / 107(13.1 \%)$ \\
\hline the Netherlands & $98 / 246(39.8 \%)$ & $2.9(3.8)$ & $79 / 98(80.6 \%)$ & $1 / 98(1.0)$ & $2 / 98(2.0 \%)$ & $4 / 98(4.1 \%)$ & & & & $12 / 98(12.2 \%)$ \\
\hline USA & $564 / 734(76.8 \%)$ & $6.2(3.9)$ & $468 / 564(83.0 \%)$ & $2 / 564(0.4 \%)$ & $4 / 564(0.7 \%)$ & $3 / 564(0.5 \%)$ & & $12 / 564(2.1 \%)$ & & $75 / 564(13.3 \%)$ \\
\hline Total sample & $1936 / 3934(49.2 \%)$ & $3.6(4.0)$ & $1385 / 1932(71.7 \%)$ & 102/1932 (5.3\%) & 63/1932 (3.3\%) & 67/1932 (3.5\%) & $29 / 1932(1.5 \%)$ & $22 / 1932(1.1 \%)$ & $15 / 1932(0.8 \%)$ & 249/1932 (12.9\%) \\
\hline
\end{tabular}

SD: Standard Deviation 


\begin{tabular}{|c|c|c|c|c|c|c|c|c|}
\hline & O্ & $\stackrel{\mathscr{S}}{\Sigma}$ & 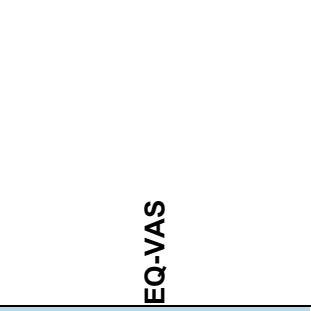 & $\begin{array}{l}\text { 占 } \\
\text { 足 } \\
\text { 至 }\end{array}$ & 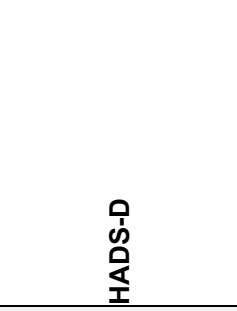 & 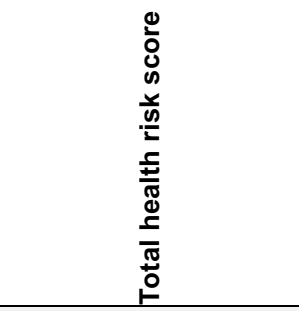 & $\begin{array}{l}\text { Dे } \\
\text { o } \\
\text { on }\end{array}$ & $\sum_{\infty}^{\infty}$ \\
\hline Argentina & $76.0(20.4) / 86.1(13.6)$ & $69.4(19.7) / 77.3(13.8)$ & $78.9(16.9) / 87.5(9.8)$ & $5.9(4.0) / 4.3(3.0)$ & $3.4(3.3) / 2.7(2.2)$ & $28.8(15.8) / 28.1(19.6)$ & $78.8(14.8) / 83.7(11.3)$ & $26.8(5.8) / 26.5(6.2)$ \\
\hline Australia & $80.1(18.4) / 73.0(20.5)$ & $71.5(17.2) / 71.2(18.7)$ & $81.6(11.6) / 75.1(16.9)$ & $5.8(3.8) / 6.2(3.7)$ & $2.9(3.0) / 3.3(3.1)$ & $23.0(17.7) / 28.5(14.8)$ & $84.2(12.4) / 82.1(15.3)$ & $26.9(6.8) / 25.3(6.5)$ \\
\hline Belgium & $75.4(23.0) / 80.0(19.2)$ & $71.4(20.9) / 76.3(16.8)$ & $77.8(14.1) / 79.5(13.9)$ & $6.1(4.4) / 5.6(3.8)$ & $3.5(4.0) / 2.4(2.7)$ & $21.7(16.0) / 24.4(17.3)$ & $76.3(16.5) / 77.5(13.2)$ & $26.3(6.1) / 25.8(5.9)$ \\
\hline Canada & $76.1(19.9) / 80.5(16.8)$ & $67.3(18.0) / 70.8(16.6)$ & $74.1(17.0) / 75.4(13.8)$ & $6.5(3.2) / 6.6(3.1)$ & $3.6(3.1) / 3.8(3.0)$ & $19.3(16.8) / 18.5(17.2)$ & $76.0(17.2) / 76.0(15.0)$ & $25.1(6.9) / 23.9(6.6)$ \\
\hline France & $68.3(25.2) / 75.2(20.1)$ & $61.1(21.3) / 67.4(20.5)$ & $76.3(19.5) / 81.21(14.4)$ & $7.9(5.0) / 6.6(3.8)$ & $4.7(3.7) / 3.3(3.4)$ & $28.1(12.6) / 30.0(17.5)$ & $76.9(16.6) / 80.0(13.6)$ & $23.6(7.1) / 25.5(6.6)$ \\
\hline India & $67.4(20.0) / 65.6(23.0)$ & $69.5(18.9) / 66.4(21.3)$ & $78.2(17.8) / 76.5(21.6)$ & $6.3(3.9) / 6.4(3.5)$ & $4.4(3.5) / 4.5(3.4)$ & $34.2(13.0) / 34.7(13.7)$ & $77.2(16.9) / 74.9(22.7)$ & $26.0(5.7) / 25.1(6.6)$ \\
\hline Italy & $74.2(21.3) / 82.5(15.5)$ & $73.5(19.3) / 79.8(15.0)$ & $78.7(15.0) / 79.9(16.0)$ & $4.6(4.3) / 4.1(3.9)$ & $3.2(3.2) / 2.7(2.4)$ & $23.1(17.3) / 29.3(15.3)$ & $79.2(14.4) / 79.7(15.1)$ & $26.4(6.4) / 25.5(6.7)$ \\
\hline Japan & $79.3(16.2) / 81.4(17.6)$ & $69.1(16.9) / 73.4(19.2)$ & $73.3(14.3) / 78.1(17.5)$ & $5.7(4.1) / 5.1(4.4)$ & $3.9(3.9) / 3.9(4.2)$ & $31.9(17.7) / 29.4(16.4)$ & $69.2(22.8) / 71.0(21.2)$ & $20.4(7.0) / 20.8(6.1)$ \\
\hline Malta & $84.7(17.6) / 87.6(9.2)$ & $77.8(17.6) / 76.6(15.0)$ & $82.8(14.8) / 80.1(12.1)$ & $5.8(4.1) / 6.1(4.5)$ & $2.4(3.3) / 2.8(2.6)$ & $31.8(16.0) / 32.5(18.9)$ & $82.2(13.0) / 74.3(13.6)$ & $26.8(5.1) / 22.4(6.7)$ \\
\hline Norway & $77.1(17.9) / 77.4(22.0)$ & $69.8(18.7) / 70.0(20.5)$ & $72.8(16.9) / 72.2(19.9)$ & $5.5(3.9) / 5.3(4.0)$ & $2.2(3.0) / 2.3(2.9)$ & $14.0(15.0) / 20.9(19.1)$ & $76.7(13.7) / 76.4(19.0)$ & $26.4(5.9) / 25.2(7.2)$ \\
\hline Sweden & $76.3(24.8) / 85.5(18.8)$ & $71.8(21.3) / 77.3(18.0)$ & $75.7(19.6) / 80.5(16.5)$ & $5.3(4.1) / 4.8(4.0)$ & $3.2(3.4) / 2.7(3.0)$ & $17.2(13.9) / 16.6(16.6)$ & $77.2(19.0) / 80.3(17.1)$ & $26.1(6.5) / 26.3(6.1)$ \\
\hline Switzerland & $79.8(20.5) / 82.0(21.6)$ & $75.9(15.9) / 76.2(18.6)$ & $80.3(15.7) / 82.7$ (16.5) & $4.5(3.3) / 4.5(3.9)$ & $2.9(3.1) / 2.9(3.4)$ & $15.8(16.7) / 19.8(16.6)$ & $81.0(15.5) / 83.0(15.3)$ & $27.4(6.0) / 26.6(6.3)$ \\
\hline Taiwan & $67.8(16.8) / 73.2(19.3)$ & $64.8(15.7) / 68.6(17.5)$ & $77.6(17.0) / 80.8(12.8)$ & $5.4(3.1) / 4.6(3.5)$ & $4.4(3.2) / 4.1(3.2)$ & $21.4(15.9) / 22.5(14.7)$ & $76.3(14.2) / 74.5(14.5)$ & $24.4(6.8) / 25.1(6.2)$ \\
\hline the Netherlands & $73.6(20.3) / 80.5(17.5)$ & $73.5(18.1) / 77.3(16.3)$ & $77.1(14.4) / 81.4(11.6)$ & $4.9(3.0) / 4.1(2.8)$ & $2.5(3.0) / 2.3(2.5)$ & $17.3(16.7) / 21.2(16.8)$ & $80.3(11.3) / 80.0(12.1)$ & $27.2(5.3) / 26.8(5.6)$ \\
\hline USA & $73.1(24.1) / 80.0(20.7)$ & $71.1(20.9) / 72.7$ (19.7) & $76.1(18.1) / 78.4(16.4)$ & $6.4(4.1) / 5.9(4.1)$ & $3.1(3.4) / 2.8(3.2)$ & $21.6(16.4) / 23.4(17.5)$ & $80.6(17.0) / 80.2(18.0)$ & $25.7(7.1) / 25.2(7.1)$ \\
\hline Total sample & $74.7(21.8) / 80.1(19.5)$ & $70.7(19.5) / 73.5(18.4)$ & $77.0(17.0) / 78.8(15.9)$ & $5.9(3.9) / 5.3(3.8)$ & $3.3(3.4) / 3.1(3.2)$ & $22.7(16.8) / 22.4(3.2)$ & $78.7(16.4) / 77.9(16.8)$ & $25.8(6.6) / 25.0(6.6)$ \\
\hline
\end{tabular}

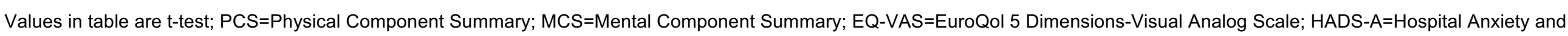

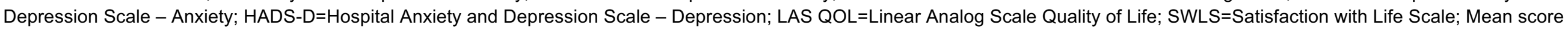
(Standard Deviation) of religious/spiritual people before slash; Mean score (Standard Deviation) of non religious/spiritual people after slash

NS. 
ONLINE TABLE 4: Univariable correlations between patient-reported outcomes and the level of importance of religion/spirituality/faith, stratified by country

\begin{tabular}{|c|c|c|c|c|c|c|c|c|}
\hline & ర్ & $\stackrel{0}{\Sigma}$ & 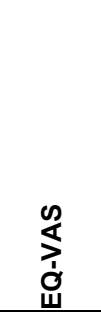 & $\begin{array}{l}\text { s. } \\
\text { مُ } \\
\text { 文 }\end{array}$ & $\begin{array}{l}\text { 号 } \\
\text { مُ } \\
\text { 文 }\end{array}$ & 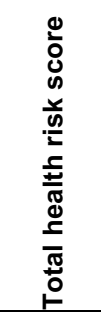 & $\begin{array}{l}J \\
\text { ơ } \\
\text { \& }\end{array}$ & $\sum_{\infty}^{\infty}$ \\
\hline Argentina & -0.230 & -0.110 & -0.124 & 0.145 & 0.013 & -0.054 & -0.079 & 0.141 \\
\hline Australia & 0.144 & -0.069 & 0.179 & 0.004 & 0.005 & -0.140 & 0.003 & 0.042 \\
\hline Belgium & -0.115 & -0.115 & -0.071 & 0.098 & 0.164 & -0.062 & -0.003 & 0.033 \\
\hline Canada & -0.115 & -0.103 & 0.009 & -0.011 & -0.069 & 0.017 & 0.063 & 0.103 \\
\hline France & -0.084 & -0.118 & -0.082 & 0.09 & 0.15 & -0.031 & -0.068 & -0.118 \\
\hline India & -0.013 & 0.132 & 0.068 & -0.041 & -0.08 & -0.044 & 0.086 & 0.054 \\
\hline Italy & -0.063 & -0.118 & -0.054 & 0.044 & -0.039 & -0.059 & -0.062 & 0.01 \\
\hline Japan & -0.092 & -0.118 & -0.137 & 0.072 & -0.009 & 0.054 & -0.028 & 0.018 \\
\hline Malta & 0.098 & 0.220 & 0.194 & -0.100 & -0.125 & -0.007 & 0.269 & 0.257 \\
\hline Norway & -0.062 & -0.026 & -0.008 & 0.05 & 0.011 & -0.184 & -0.049 & 0.062 \\
\hline Sweden & -0.210 & -0.128 & -0.120 & 0.084 & 0.086 & 0.05 & -0.092 & -0.038 \\
\hline Switzerland & 0.097 & -0.083 & -0.106 & 0.027 & 0.021 & -0.09 & -0.044 & 0.064 \\
\hline Taiwan & -0.173 & -0.111 & -0.059 & 0.138 & 0.04 & -0.08 & 0.121 & -0.023 \\
\hline the Netherlands & -0.187 & -0.119 & -0.156 & 0.141 & 0.004 & -0.126 & 0.000 & 0.006 \\
\hline USA & -0.07 & 0.024 & 0.012 & 0.028 & 0.015 & -0.092 & 0.103 & 0.120 \\
\hline Total sample & -0.134 & -0.062 & -0.029 & 0.085 & 0.019 & 0.017 & 0.06 & 0.085 \\
\hline
\end{tabular}

Values in table are Spearman's correlation coefficients; PCS=Physical Component Summary; MCS=Mental Component Summary; EQ-VAS=EuroQol 5 Dimensions-Visual Analog Scale; HADS-A=Hospital Anxiety and Depression Scale - Anxiety; HADS-

$\mathrm{D}=$ Hospital Anxiety and Depression Scale - Depression; LAS QOL=Linear Analog Scale Quality of Life; SWLS=Satisfaction with Life Scale; 
ONLINE FIGURE 1. The relationship between religion/spirituality and patient-reported outcomes, moderated by country level of religiosity/secularity

Panel A: Relationship between being religious/spiritual and mental health

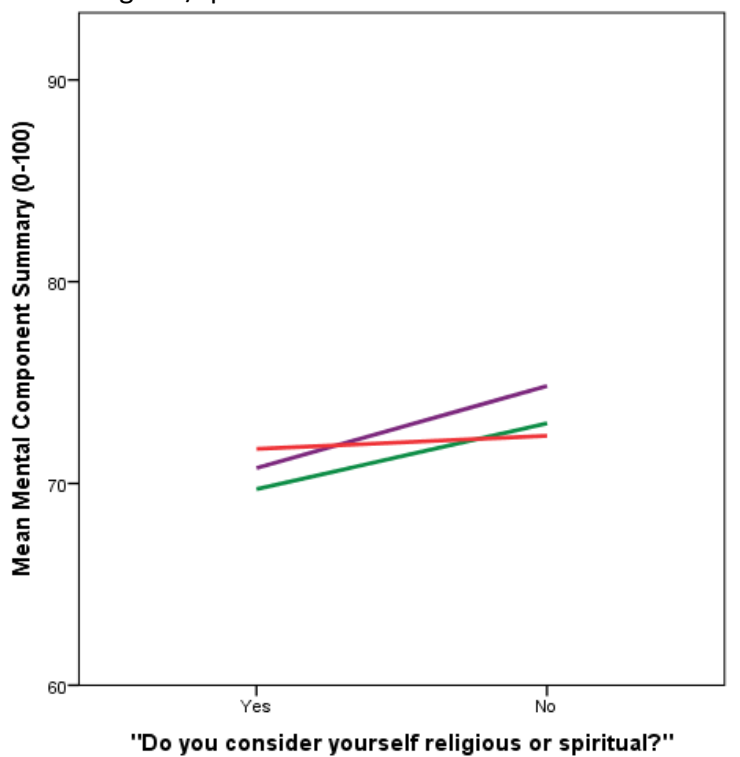

Panel C: Relationship between the level of importance of religion/spirituality and mental health

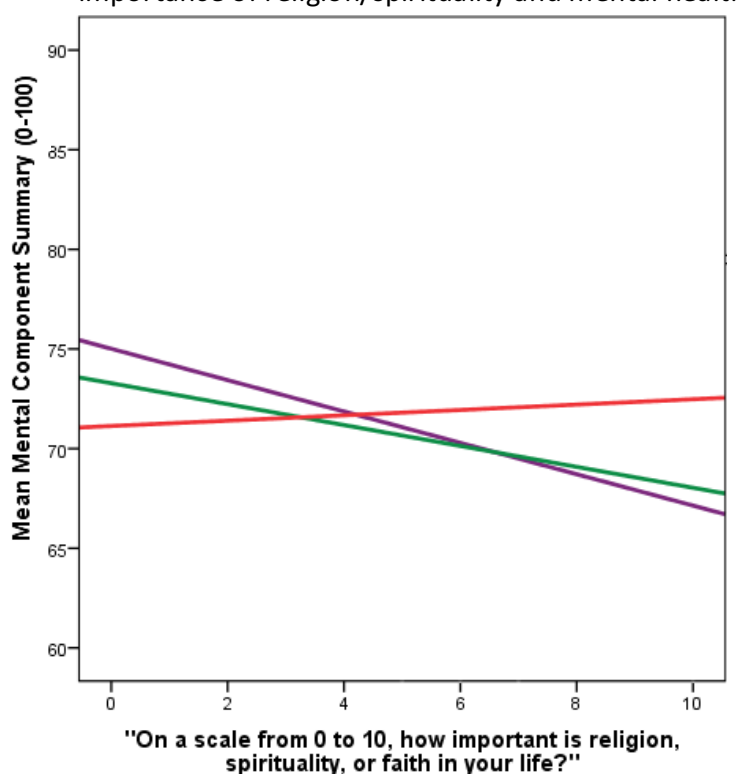

Panel B: Relationship between the level of importance of religion/spirituality and physical health

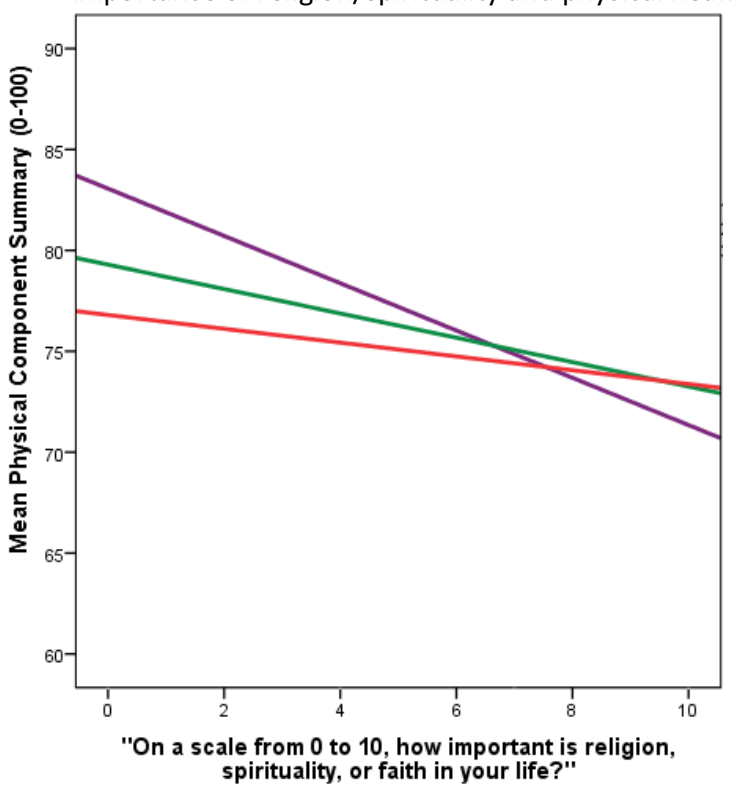

Panel D: Relationship between the level of importance of religion/spirituality and depressive symptoms

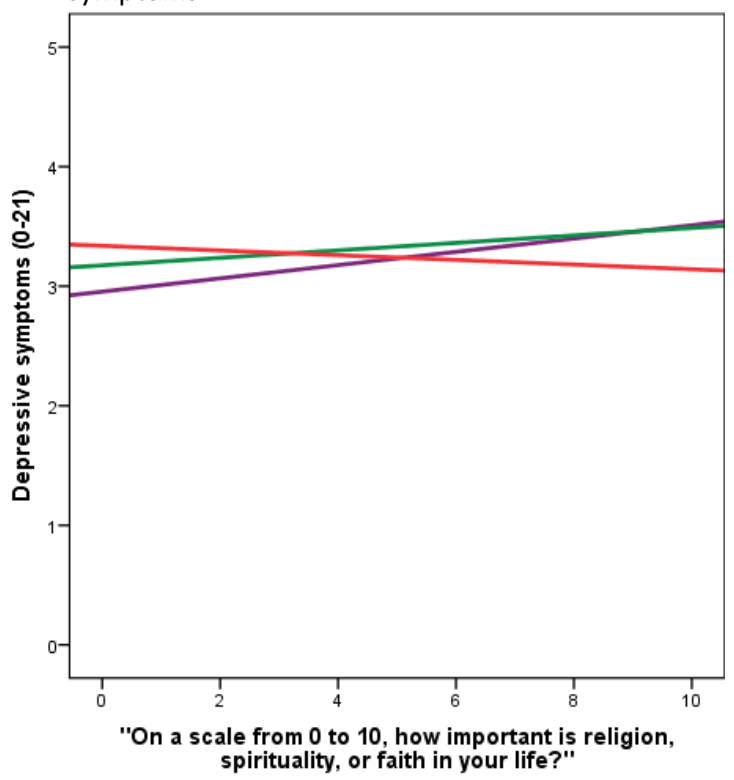

Secular countries based on Gallup Poll

Moderately religious countries based on Gallup Poll

Highly religious countries based on Gallup Poll 